\title{
Food motivation of rehabilitated malnourished rats: Implications for learning studies
}

\author{
EDWARD S. HALAS, PATRICIA A. BURGER, and HAROLD H. SANDSTEAD \\ University of North Dakota, Grand Forks, North Dakota 58202 \\ and United States Department of Agriculture, Science and Education Administration \\ Human Nutrition Laboratory, Grand Forks, North Dakota 58202
}

\begin{abstract}
Adult male.and female rats that had suffered either postnatal undernutrition or postnatal zinc deficiency were more highly motivated for food than normal rats. A progressive ratio schedule was used to test the rats for food motivation. All rats were deprived of food $24 \mathrm{~h}$ prior to testing. Each rat was tested once a week for 8 consecutive weeks. The smaller body size of the previously malnourished rats relative to their body surface area seemed to be the best explanation for their higher level of motivation.
\end{abstract}

Several studies (Baird, Widdowson, \& Cowley, 1971; Brown, Mostofsky, \& Warren, 1973; Cowley \& Griesel, 1966; Lokken, Halas, \& Sandstead, 1973; O'Connell, Yeaton, \& Strobel, 1978; Ottinger \& Tanabe, 1968) have shown that prenatal and postnatal malnutrition impair subsequent performance of animals on learning tasks that involve food motivation. These experiments have been difficult to interpret because the food motivation of animals that have been exposed to early malnutrition may not be the same as normal animals. Some investigators (Baird, Widdowson, \& Crowley, 1971; Crnic, 1976; Smart, 1977) were aware of this and other problems and cautioned that their findings and those of others were too erratic to delineate the cause of the poor performance of the animals. Their caution is worthy of note. Attempts have been made to measure the food motivation of rehabilitated rat offspring, and the reports have been conflicting. In one study (Cravens, 1974), it was found that previously malnourished rats were less motivated for food, while in another (Smart, Dobbing, Adlard, Lynch, \& Sands, 1973), just the opposite was observed. The purpose of this experiment was to compare the food motivation of rats that had suffered two different types of postnatal malnutrition with the food motivation of normal rats.

This work was supported in part by USDA Cooperative Agreement No. 12-14-3001-294 with the University of North Dakota. Mention of a trademark or proprietary product does not constitute a guarantee or warranty of the product by the U.S. Department of Agriculture, and does not imply its approval to the exclusion of other products that may also be suitable. Reprint requests should be sent to Dr. E. Halas, Department of Psychology, University of North Dakota, Grand Forks, North Dakota 58202 .

\section{EXPERIMENT 1}

\section{Method}

Animals. Thirty pregnant Long-Evans rats were purchased from the Charles Rivers Co. The dams were individually housed in plastic cages and were fed a zinc-deficient diet (TD 71305; Teklad Mills, Madison, Wisconsin) plus zinc-supplemented water (25 ppm $\mathrm{Zn}$ ). On the day of delivery, the zinc supplementation of 10 dams was discontinued and they were started on double-glass-distilled deionized water; the diet was continued ad lib. These dams were the zinc-deficient group (ZD). Ten pair-fed (PF) dams were individually paired by weight with rats in the $\mathrm{ZD}$ group and given the same quantity of the diet as consumed the previous day by their ZD pairmates. The PF dams were continued on the zincsupplemented water. Because of the anorexia in the ZD group, they became undernourished. The remaining 10 dams were fed the diet ad lib (AL) after delivery and given the zinc-supplemented water. The AL-group animals were the normal controls. Twentyfour hours after delivery, all litters were reduced to the nine most healthy appearing pups. The food consumption and the weights of the dams and their litters were recorded daily. On the 22 nd day, all dams and their litters were fed Purina Chow and tap water ad lib. Because of the weakened condition of the $\mathrm{ZD}$ and PF pups, the pups, including AL pups, were not removed from their dams until the 25th day. The offspring were fed the chow ad lib for the duration of the experiment, except when they were tested for food motivation. The dams and their litters were kept in a wellventilated room at a temperature of $24^{\circ} \mathrm{C}$ and a 12 -h day/night cycle. The litters were segregated by sex at 40 days of age and placed two to a stainless steel cage. At 75 days, the rats were placed in individual steel cages for the next 9 weeks.

Twelve rats, six males and six females, were selected from each of the three dietary groups, for a total of 36 rats. The $12 \mathrm{ZD}$ rats were selected from six litters, while the $12 \mathrm{PF}$ and $12 \mathrm{AL}$ rats were selected from seven and six litters, respectively. Only those litters whose dams successfully raised at least eight pups were used. All eligible litters contributed pups to the experiment.

Training and testing procedures. One week prior to the testing sessions, all rats were trained to barpress for food in operant boxes. The rats remained in the operant boxes for $24 \mathrm{~h}$ and were allowed to feed freely on a continuous reinforcement schedule. The reinforcement was $45-\mathrm{mg}$ Noyes pellets. On the average, the AL males consumed $600 \pm 136$ pellets during this period, while the PF and ZD males consumed $622 \pm 98$ and $571 \pm 82$ pellets, respec- 
tively. For the AL females, the mean and standard deviation were $475 \pm 108$, while the $P F$ and $Z D$ females were $517 \pm 57$ and $466 \pm 108$, respectively. None of the differences among the male or female groups were statistically significant. After training, each rat was tested once a week for 8 consecutive weeks. The rat was deprived of food for $24 \mathrm{~h}$ prior to its testing session. The weight of the rat before and after the 24-h deprivation period was recorded. At all other times, the rat was fed chow ad lib. The testing procedure for the 36 rats was as follows. Six rats, 2 from each dietary group, were tested every day. Males were run on Monday, Wednesday, and Friday, while the females were run on Tuesday, Thursday, and Saturday. Each group of 6 rats was always run on the same day of the week. The 6 rats were put in six operant boxes which were individually isolated in large sounddeadened boxes. Each operant box was equipped with an intake and exhaust ventilating system which provided both fresh air and a constant masking noise to eliminate external sounds. The elimination of external noise was confirmed by repeated attempts to disrupt the steady rate of barpressing with loud, external sounds, which proved to be futile. The 28 -V houselight in the operant box was always on and the attached water bottle was full.

To test for food motivation, the progressive ratio schedule was selected because it is a very sensitive method for measuring motivation (Hodos, 1961; Stewart, 1975). It has been infrequently used by others due to the large amount of time required to run an experiment (Stewart, 1975). In the present experiment, the ratio was increased by an increment of one with each successful completion of a ratio, that is, the rat pressed the lever once for the first pellet, twice for the second pellet, three times for the third pellet, and so on. An electronic control system automatically recorded the barpresses and increased the ratio by one whenever a rat completed a ratio and received a pellet of food. Six electronic timers were attached to the control system; if a rat failed to press the lever for $15 \mathrm{~min}$, the session for that rat was automatically terminated. The 15-min termination period was designated the "breaking point" (Hodos, 1961); the last completed ratio was the measure of the rat's level of motivation. If the rat pressed the lever before the expiration of the 15-min period, the timer was automatically reset to zero. After a rat reached its 15-min "breaking point," it was returned to its cage until its next testing session the following week. The rat was then fed ad lib until the next $24 \mathrm{~h}$ fooddeprivation period.

\section{Results}

Food consumption of the dams is shown in Figure 1. A two-way analysis of variance (Groups by

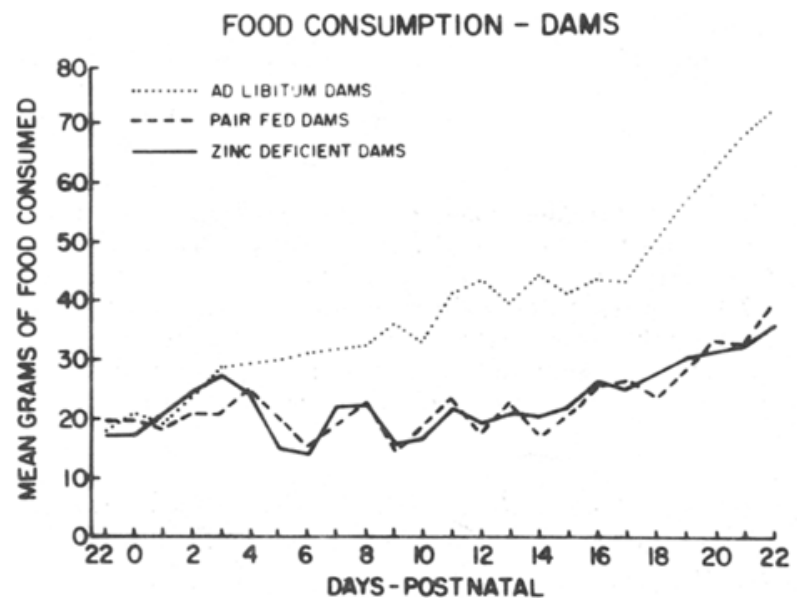

Figure 1. Food consumption of dams during the lactation period. The $A L$ dams ate significantly more food than either the PF or ZD dams. Day 0 is day of birth.

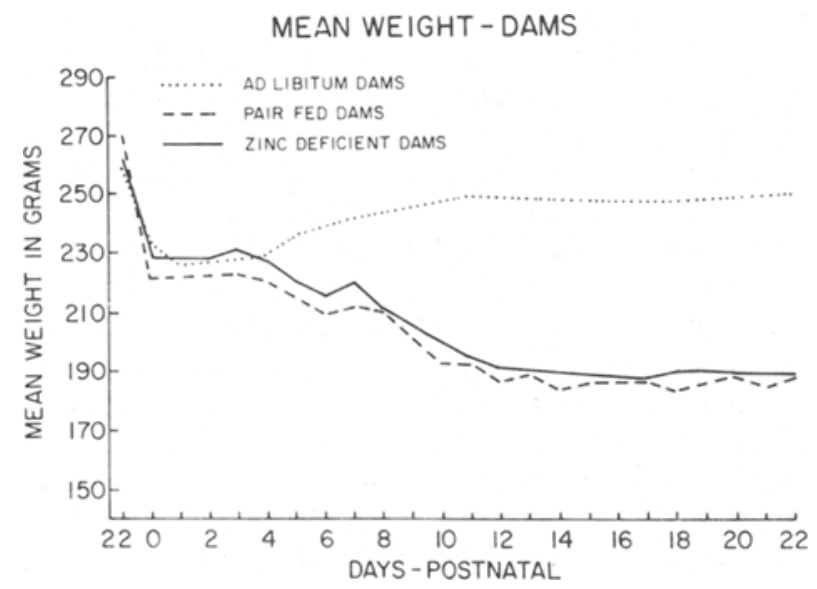

Figure 2. Mean weights of dams during the lactation period. The AL dams weighed significantly more than the PF and $Z D$ dams.

Days) with repeated measures on one variable was used to test for significance among the three groups and for internal comparisons. Prior to delivery, there were no differences among the three groups $(p>.05)$. Day 0 is the day of birth. After delivery, the $Z D$ group displayed anorexia and consumed significantly less food than the AL group $[F(1,10)=46.32$, $\mathrm{p}<.001$ ]. The PF dams were given the same quantity of the diet as consumed by their ZD match mates. The discrepancies between the ZD and PF dams, which were not statistically significant, were due to individual dams being dropped from the experiment because they could not maintain at least eight pups through the weaning period. The surviving pairmate dam was kept in the experiment if she successfully nursed at least eight pups through weaning. She was paired with a dam of the outer group that had an equivalent weight. The weights of the $\mathrm{ZD}$ and $\mathrm{PF}$ dams were adversely affected by the diet (Figure 2). During the lactation period, both groups weighed significantly less (ZD vs. $A L, p<.01$; PF vs. $A L$, $\mathrm{p}<.01)$ than the AL dams. There were no significant differences between the ZD and PF dams. None of the interactions were significant.

The weights of the ZD and PF pups were also affected by the diet consumed by their dams (Figure 3 ). The overall differences among the three groups was significant $(\mathrm{p}<.05)$. Both the $\mathrm{ZD}$ and PF pups weighed significantly less than the AL pups ( $Z D$ vs. AL, p <.01; PF vs. AL, p < .01). There were no significant differences between the $Z D$ and PF pups. All three groups rapidly gained weight, but the weight of $Z D$ and $P F$ pups did not catch up to the weight of AL pups by the 40th day. After weaning, the AL pups consumed more food than either the ZD or PF pups (ZD vs. AL, $\mathrm{p}<.01$; PF vs. AL, $\mathrm{p}<.05$ ). There were no significant differences between the $Z D$ and PF pups.

The mean total barpresses ("breaking points") for 
the three dietary groups are shown in Figure 4. To better illustrate the amount of work required to reach the breaking point, the ratios were converted to total barpresses. For example, to finish 100 ratios and therefore receive 100 pellets of food required 5,050 barpresses, while 80 ratios required 3,240 barpresses. All groups (except the ZD males) exhibited an initial increase in mean total barpresses, followed by a gradual drop until an asymptote was reached. This pattern is typical of rat behavior on a progressive ratio schedule (Stewart, 1975). Inspection of Figure 4 shows that the previously undernourished rats (PF males and females) consistently had the highest breaking point. The $\mathrm{ZD}$ males and females were intermediate, and the normal rats (AL males and females) had the lowest breaking point. The overall analysis of variance was significant for both males $(p<.05)$ and females $(p<.05)$. Differences between the $P F$ and AL males were significant $(p<.01)$, as were the differences between the PF and AL females $(p<.01)$. The PF males and females were also significantly different from ZD males $(p<.05)$ and females $(p<.05)$, respectively. ZD males and females differed significantly from AL males $(p<.05)$ and females $(p<.05)$, respectively. None of the interactions were significant.

To illustrate the differences among the groups, the $\mathrm{ZD}, \mathrm{PF}$, and AL males averaged 4,037, 4,862, and 2,625 leverpresses, respectively, for the 8-week period. For the same time period, the $\mathrm{ZD}, \mathrm{PF}$, and AL females averaged 4,535, 5,625, and 3,045 barpresses, respectively.

Since body weight may be related to food motivation (Smart \& Dobbing, 1977), the mean body weights of the rats just before their testing sessions are shown in Figure 5. The AL males were consistently heavier than the $\mathrm{PF}$ and $\mathrm{ZD}$ males (AL vs. $\mathrm{PF}, \mathrm{p}<.05$;

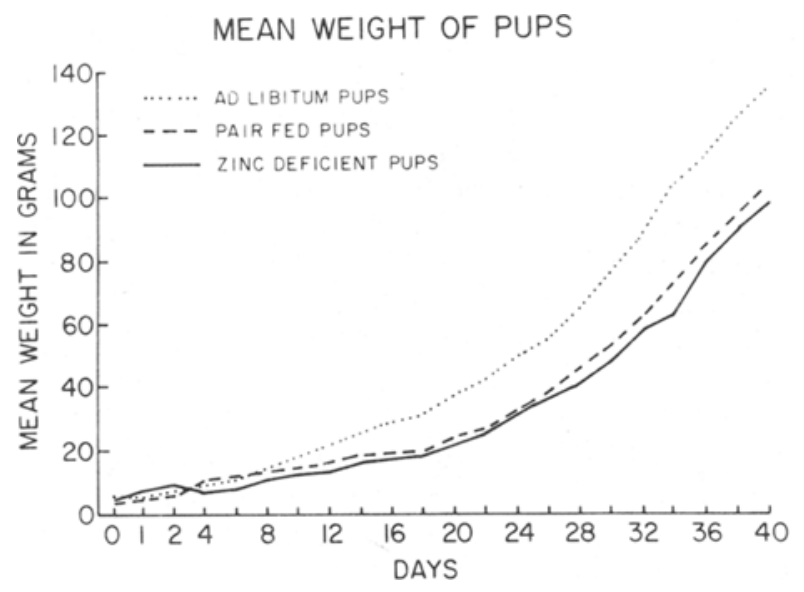

Figure 3. Mean weights of pups from day of birth through 40th day. The $A L$ pups weighed significantly more than the PF and $Z D$ pups.
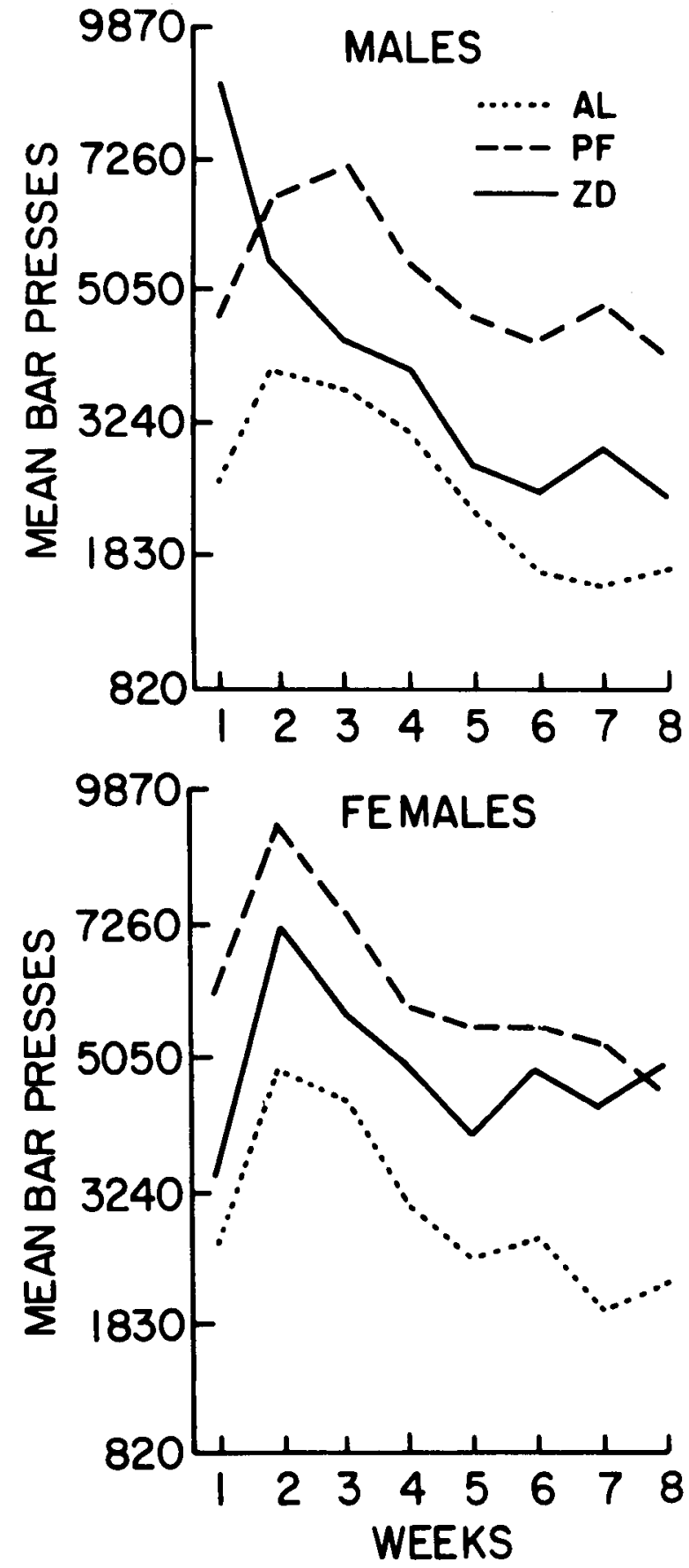

Figure 4. Breaking points of males and females converted to mean total barpresses. A breaking point of 100 ratios required 5,050 barpresses, while a breaking point of 80 ratios required 3,240 barpresses. For both males and females, the $P F$ rats had significantly higher breaking points than the $\mathrm{ZD}$ rats, which, in turn, had significantly higher breaking points than $A L$ rats. All rats were tested once a week for 8 consecutive weeks.

AL vs. $Z D, p<.05$ ), while the $A L$ females were significantly heavier than the $\mathrm{PF}$ and $\mathrm{ZD}$ females (AL vs. $\mathrm{PF}, \mathrm{p}<.05$; $\mathrm{AL}$ vs. $\mathrm{ZD}, \mathrm{p}<.05$ ). There were no significant differences between the $\mathrm{PF}$ and $\mathrm{ZD}$ males or between the PF and ZD females. As expected, the 
mean body weights for all groups increased during the 8-week period (Figure 5), while the breaking points (Figure 4) decreased during the same period. These results appear to lend support to the hypothesis that motivation is influenced by body weight (Smart \& Dobbing, 1977). However, the PF males and females had consistently higher breaking points than the $\mathrm{ZD}$ males and females, but there were no significant differences between their body weights, a finding in conflict with this hypothesis.

The above results suggested that body weight might not be a critical factor in the explanation of food motivation for nutritionally rehabilitated rats. Since body weights of even normal rats can vary widely, it has been suggested that percent weight loss is the best antecedent index of the rat's motivation (Bolles, 1967, p. 154). Therefore, the percent of weight loss over the 24-h deprivation period was computed. Although the AL males and females weighed signifi-
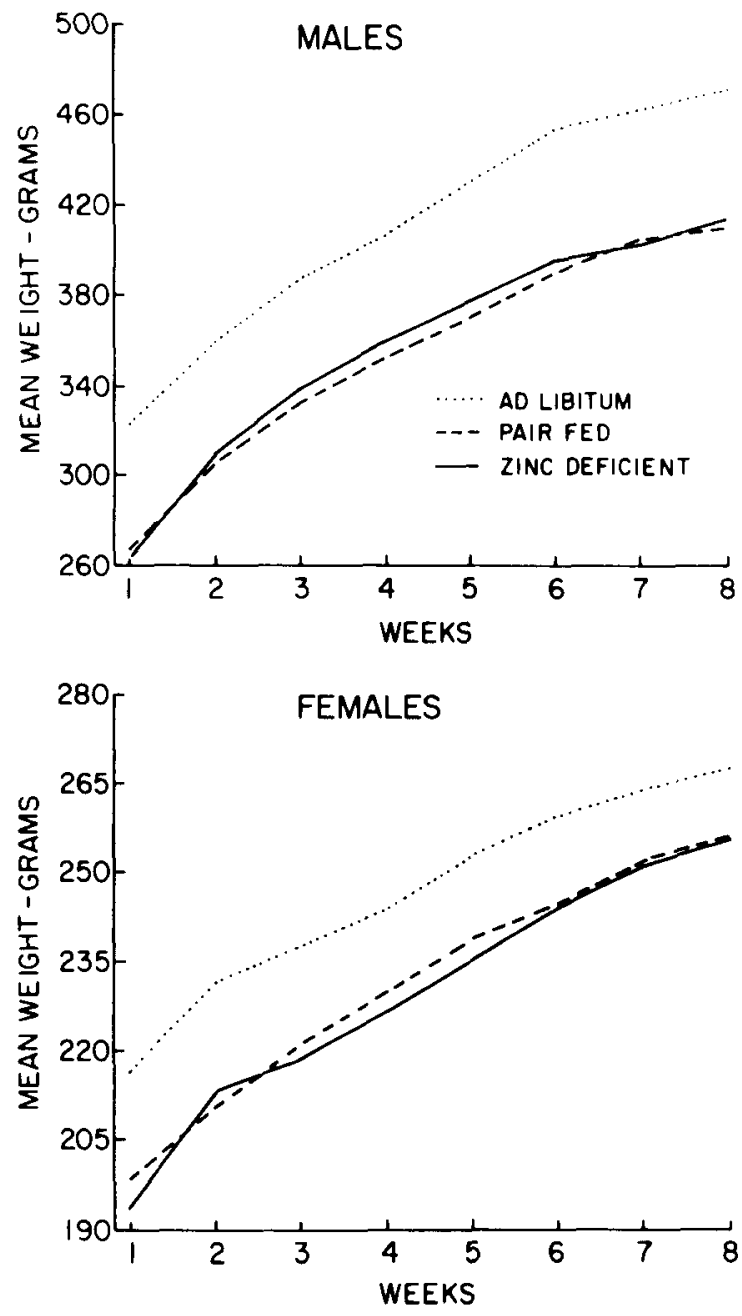

Figure 5. Mean weights of males and females during the period they were tested for food motivation. Weights were recorded after a 24-h food-deprivation period. For both males and females, the $A L$ rats weighed significantly more than the $P F$ and $Z D$ rats. cantly more than the PF and $\mathrm{ZD}$ males and females (Figure 5), there were no significant differences in percent weight loss among the males $(p>.05)$ or females $(p>.05)$. It is clear that normal $(A L)$ and rehabilitated rats (PF and $Z D$ ) lose the same percent of body weight over a 24 -h deprivation period. Percent of weight loss does not provide an explanation for the increased motivation of $P F$ and $Z D$ rats.

\section{Discussion}

The results are unequivocal. Rats that suffered postnatal undernutrition (PF) or postnatal zinc deficiency $(Z D)$ were more highly motivated for food than normal rats (AL) after a 24-h deprivation period. The explanation for the higher level of motivation is not known, but a hypothesis has been presented (Smart \& Dobbing, 1977). Essentially, the hypothesis states that rehabilitated rats, because of a greater body surface relative to their smaller body weights, have a different basal metabolic rate which requires more food. Much of our data support this hypothesis, except that the ZD rats were not as highly motivated as the PF rats even though both groups had equivalent body weights. If speculation is permitted, there is the possibility that the anorexia suffered by the ZD dams may have also occurred among their pups, since the zinc levels of the milk of $\mathrm{ZD}$ dams has been found to be significantly reduced and their pups were zinc deficient (Mutch \& Hurley, 1974). Zinc deficiency causes, among other things, a loss of appetite, which contributes to the undernutrition. A loss of appetite by the ZD pups in our experiment during the suckling period might have blunted the psychological effects of the undernutrition. Both the ZD and PF pups were undernourished during the lactation period, but the motivation for food among the ZD pups was probably reduced due to the anorexia. Thus the $\mathrm{ZD}$ pups would not have suffered the pangs of starvation nearly as much as the PF pups, which received adequate zinc and therefore suffered no reduction in appetite. This may explain why the motivation of the $\mathrm{ZD}$ rats was not as high as that of the PF rats.

Different procedures for implementing food motivation may well produce different results. The present research involved a $24-\mathrm{h}$ food deprivation period prior to testing, which resulted in a consistent percent weight loss. Our data would appear to conflict with the findings of Rixon and Stevenson (1957). Rixon and Stevenson observed that the percent of weight loss of rats that were allowed to starve to death varied widely and that those rats with the highest percent weight loss also had the highest metabolic rate. Smart and Dobbing (1977) hypothesized that heavier rats would have a lower metabolic rate and would therefore be less motivated for food. Our data support the Smart and Dobbing hypothesis. 
This conflict is readily resolved when the duration of the food deprivation in the two experiments as well as the initial weights of the animals are taken into account. Rixon and Stevenson continued the deprivation until death, and percent of weight loss was calculated at that point, while we limited our food deprivation for a period of $24 \mathrm{~h}$. The initial weight of the rats is also a factor, since our AL rats were significantly heavier than the PF and $Z D$ rats. Although they were not directly studying initial weights, Rixon and Stevenson state "while the heavier rats tended to survive longer they also tended to have lower metabolic rates"' (p. 335). This statement is in agreement with the Smart and Dobbing hypothesis and our data. As stated by Rixon and Stevenson, there are several "factors which influence metabolic rate and consequently the rate at which body stores and proteins are utilized"' (p. 335). Our research suggests that postnatal malnutrition is another factor that can influence metabolic rate and ultimately food motivation.

\section{EXPERIMENT 2}

Experiment 1 demonstrated that previously malnourished rats were more highly motivated for food than normal rats. Rather than have an exact replication of Experiment 1, it was decided to modify the preliminary training of the rats for Experiment 2 . It was our intention not only to reproduce the phenomenon observed in Experiment 1, but to replicate the results under somewhat different, and perhaps disadvantageous, conditions. It was hypothesized that the additional preliminary training would establish consistent lever response habits among the groups and therby obscure the differences in motivation between the groups.

\section{Method}

Animals. The 30 pregnant Long-Evans dams purchased from the Charles Rivers Co. were given the same care and experimental treatment as described in Experiment 1. Their offspring were selected in the same manner.

Training and testing procedure. Two weeks prior to the testing sessions, all rats were trained to barpress for food on a continuous reinforcement schedule. During the 2 nd week, all rats were given VI training for $2 \mathrm{~h}$ per day for 4 days. On the first day of VI training, the rats were given a VI $15-\mathrm{sec}$ schedule for the 1st hour followed by a VI 90 -sec schedule for the 2 nd hour. The rats continued on the VI $90-\mathrm{sec}$ schedule for the 2 nd, 3rd, and 4th day of preliminary training. No supplemental food was given to the rats during the VI training period. On the last day of VI training, the $\mathrm{AL}$ males averaged $2,006 \pm 210$ barpresses while the PF and ZD males averaged $2,015 \pm 591$ and $2,244 \pm 500$ barpresses, respectively. The AL females averaged $2,558 \pm 889$ barpresses, while the PF and ZD females averaged 2,332 \pm 629 and $1,949 \pm 460$ barpresses, respectively. None of the differences among the male or female groups were statistically significant. After the VI training, the rats were fed ad lib until the following week when they began their testing sessions, which were identical to those described in Experiment 1.

\section{Results and Discussion}

Food consumption and weight gains of the dams and their offspring were not significantly different from those reported in Experiment 1, and therefore are not shown.

The overall differences in mean barpresses (Figure 6) among the males were significant $(p<.05)$. The AL males emitted significantly fewer leverpresses than the PF $(p<.01)$ and ZD males $(p<.05)$. There
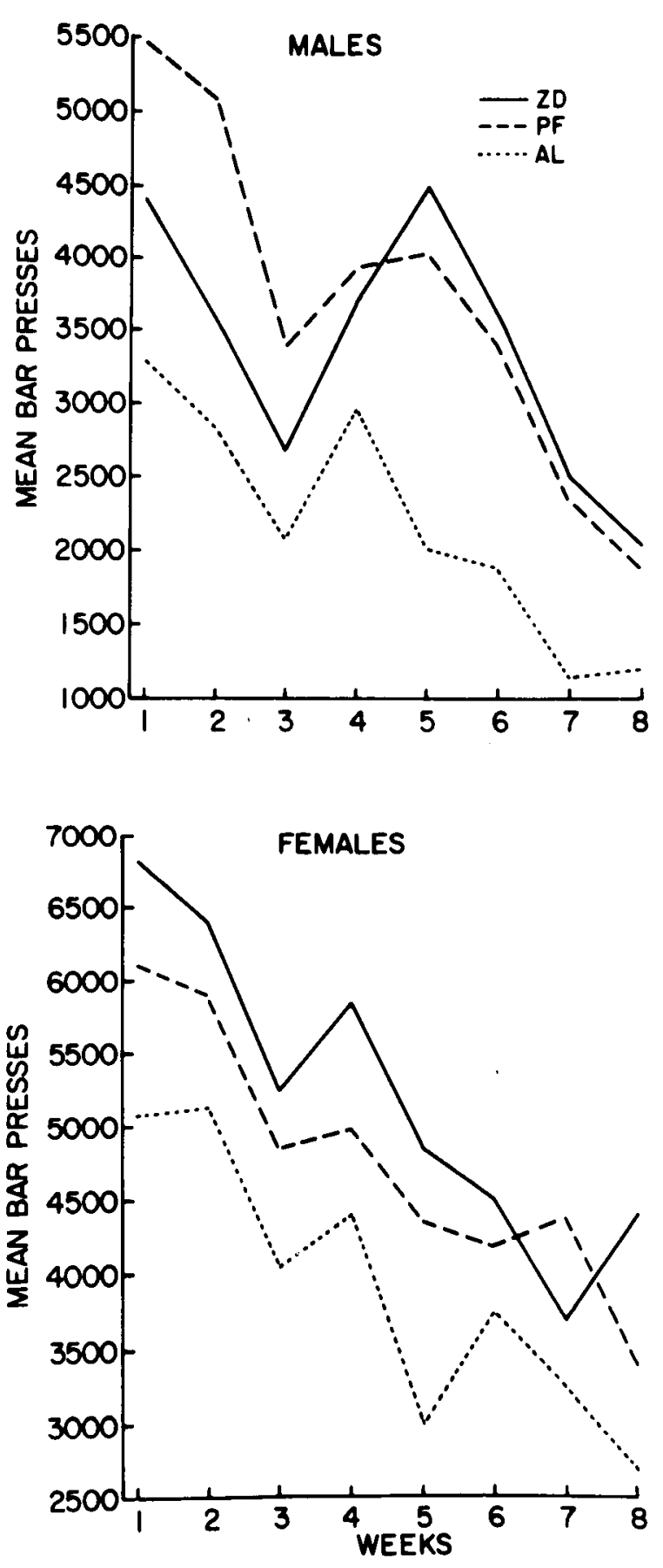

Figure 6. Mean total barpresses of male and female rats. 
were no significant differences between the PF and ZD males $(p>.05)$. None of the interactions were significant.

Among the females, there were significant differences in lever responses $(p<.05)$. The mean responses for the AL females was significantly less than those for the PF $(p<.05)$ and ZD females $(p<.05)$. There were no significant differences between the PF and $\mathrm{ZD}$ females. None of the interactions were significant.

Again to illustrate the differences among the groups, the overall mean leverpresses for the 8-week period was $3,387,3,712$, and 2,200 , respectively, for the $\mathrm{ZD}, \mathrm{PF}$, and $\mathrm{AL}$ males. For the same time period, the $Z D, P F$, and $A L$ females averaged $5,212,4,920$, and 3,937 barpresses, respectively.

Despite the differences in preliminary training between Experiments 1 and 2, a single conclusion can be made. Early postnatal malnutrition increases the food motivation of adult rats. There were, however, some differences in results between the two experiments. Unlike the rats in Experiment 1, the rats in Experiment 2 did not have an increase in response rate from the 1 st to the 2 nd week. In general, the rats in Experiment 2 had their highest response rate during the 1st week and then gradually declined. The ZD males were more erratic and did not follow this trend. Interestingly, the ZD males in Experiment 1 were also erratic and did not follow the trend of the other groups.

\section{GENERAL DISCUSSION}

The implications of our findings for studies in which the learning or intellectual abilities of animals that have been exposed to early malnutrition are tested are obvious. Performance of a learning task is affected by two critical variables: learning ability and motivation. When learning is studied, the motivation of the animals must be constant; otherwise, a difference in performance cannot be attributed only to a difference in learning ability. These difficulties of interpretation are further complicated when the Yerkes-Dodson law is taken into consideration (Yerkes \& Dodson, 1908). They observed that performance in a learning task improved with increased motivation up to an optimum, at which point performance deteriorated as motivation continued to be increased. For easy learning problems, high levels of motivation were best, while difficult problems were more readily solved using lower levels of motivation. The significance of this law for learning experiments studying rehabilitated malnourished animals is obvious. For any given learning task, one group's motivation may be at an optimal level but the motivation of the other group(s) may be too high or low.
Results of learning studies obtained under such conditions would be difficult to interpret.

Other forms of motivation have been used to test the learning ability of malnourished animals (Bush \& Leathwood, 1975; Giurintano, 1974; Halas \& Sandstead, 1975; Simonson \& Chow, 1970), but the results are open to more than one interpretation. For example, water reward, rather than food reward, was used to test previously malnourished rats (Simonson \& Chow, 1970). The authors concluded that the previously malnourished rats suffered neurological abnormalities and inefficient learning abilities (Simonson \& Chow, 1970). It has since been reported that rats exposed to early malnutrition are more highly motivated for water than normal rats (Smart $\&$ Dobbing, 1977). This finding complicates the interpretation of data from water-reward experiments.

Clinical evidence suggests that early malnutrition may, indeed, seriously impair subsequent learning abilities of humans (Winick, 1974). However, human malnutrition is usually caused by deficiencies of many components of the diet, and the occurrence of malnutrition is usually associated with social or cultural disadvantages. With so many deficits inpinging on the human, it is impossible to specify the exact cause of the mental impairment. Animal experiments are intended to help specify the contribution of various dietary components to normal development, but, unfortunately, what would appear to be a straightforward empirical question has proven to be, on close examination, a very difficult problem.

\section{REFERENCES}

Baird, A., Widdowson, E. M., \& Cowley, J. J. Effects of calorie and protein deficiencies early in life on the subsequent learning ability of rats. British Journal of Nutrition, 1971, $25,391-403$.

Bolles, R. C. Theory of motivation. New York: Harper \& Row, 1967

Brown, W. G., JR., Mostofsky, D. I., \& Warren, S. A. Protein deficiency and performance of pigeons on a multiple schedule of reinforcement. Developmental Psychobiology, $1973,7,1-6$.

Bush, M., \& Leathwood, P. D. Effect of different regimens of early malnutrition on behavioral development and adult avoidance learning in Swiss white mice. British Journal of Nutrition, 1975, 33, 373-385.

Cowley, J. J., \& Griesel, R. D. The effect on growth and behavior of rehabilitating first and second generation low protein rats. Animal Behavior, 1966, 14, 506-517.

Cravens, R. W. Effects of maternal undernutrition on offspring behavior: Incentive value of a food reward and ability to escape from water. Developmental Psychobiology, 1974, 7, 61-69.

CrNic, L. S. Effects of infantile undernutrition on adult learning in rats: Methodological and design problems. Psychological Bulletin, 1976, 83, 715-728.

Giurintano, S. L. Effects of protein-calorie deficiencies on the learning ability of the Wistar rat. Physiology \& Behavior, 1974, 12, 55-59. 
Halas, E. S., \& Sandstead, H. H. Some effects of prenatal zinc deficiency on behavior of the adult rat. Pediatric Research, 1975, 9, 94-97.

Hodos, W. Progressive ratio as a measure of reward strength. Science, 1961, 134, 943-944.

Lokken, P. M., Halas, E. S., \& Sandstead, H. H. Influence of zinc deficiency on behavior. Proceedings of the Society for Experimental Biology and Medicine, 1973, 144, 680-682.

Mutch, P. B., \& Hurley, L. S. Effect of zinc deficiency during lactation on postnatal growth and development of rats. Journal of Nutrition, 1974, 104, 828-842.

O'Connell, M. F., Yeaton, S. P., \& Strobel, D. A. Visual discrimination in the protein-malnourished Rhesus. Physiology \& Behavior, 1978, 20, 251-256.

Ottinger, D. R., \& Tanabe, G. Maternal food restriction: Effects on offspring behavior and development. Developmental Psychobiology, 1968, 2, 7-9.

Rixon, R. H., \& Stevenson, J. A. F. Factors influencing survival of rats in fasting metabolic rate and body weight loss. American Journal of Physiology, 1957, 188, 332-336.

Simonson, M., \& Chow, B. F. Maze studies on progeny of underfed mother rats. Journal of Nutrition, 1970, 100, 685-690.

SMART, J. L. Early life malnutrition and later learning ability:
A critical analysis. In A. Oliverio (Ed.), Genetics, Environment and Intelligence. Amsterdam: Elsevier/North-Holland Biomedical Press, 1977.

Smart, J. L., \& Dobbing, J. Increased thirst and hunger in adult rats undernourished as infants: An alternative explanation. British Journal of Nutrition, 1977, 37, 421-430.

Smart, J. L., Dobbing, J., Adlard, B. P. F., Lynch, A., \& SANDS, J. Vulnerability of developing brain: Relative affects of growth restriction during the fetal and suckling periods on behavior and brain composition of adult rats. Journal of Nutrition, 1973, 103, 1327-1338.

Stewart, W. J. Progressive reinforcement schedules: A review and evaluation. Australian Journal of Psychology, 1975, 27, 9-22.

WıNıск, M. Nutrition and fetal development. New York: Wiley, 1974.

YeRkes, R. M., \& DoDson, J. D. The relation of strength of stimulus to rapidity of habit-formation. Journal of Comparative Neurology and Psychology, 1908, 18, 459-482.

(Received for publication February 9, 1979; revision accepted July 26,1979 .) 